\title{
Comparative Study to Evaluate Efficacy \& Cost Effectiveness of Olmesartan versus Telmisartan, In Patients of Stage I Hypertension
}

\author{
Pankaj Kumar Singh ${ }^{1}$, Sameer Kumar ${ }^{2}$ \\ ${ }^{1}$ Tutor, Department of Pharmacology, Vardhman Institute of Medical Sciences, Pawapuri, Nalanda, Bihar, ${ }^{2}$ Associate Professor, Department of Pharmacology, \\ Vardhman Institute of Medical Sciences, Pawapuri, Nalanda, Bihar.
}

\section{Abstract}

Background: Hypertension is one of the most common diseases in the world. It is an important and independent risk factor for atherosclerosis, heart failure, renal disease, and peripheral arterial disease. It is directly responsible for $57 \%$ of all stroke deaths and $42 \%$ of coronary heart disease deaths in India. Aims and Objectives: To evaluate and compare efficacy and cost effectiveness in hypertensive patients receiving Olmesartan and Telmisartan in Stage I hypertension Subjects and Methods: The present study was an open, prospective, randomized, parallel group comparative study conducted in 60 patients of stage I hypertension over a period of 16 weeks. Patients were randomly allocated to two, age and sex, matched groups of 30 patients each. Group I patients were started on Olmesartan at a dose of 20 mg \& Group II patients were put on Telmisartan at a dose of $40 \mathrm{mg}$. The BP lowering efficacy and cost effective analysis of Olmesartan versus Telmisartan was calculated \& compared. The data was entered in Microsoft excel and compiled. Statistical analysis was done using various tests. Results: Maximum patients in both the groups were in age group of 51-60 years. In group I there were 13 males and 17 females. In group II there were 14 males and 16 females. Both Olmesartan and Telmisartan are effective in lowering systolic \& diastolic BP in supine \& sitting positions \& mean BP is also lowerer, more in Olmesartan group. By cost effective analysis Telmisartan was found more cost effective. Incremental cost effective ratio was found to be 218.35. Conclusion: Both Olmesartan and Telmisartan belong to the same antihypertensive drug class, effectively reduce systolic and diastolic blood pressure at various visits. Taking into account Total cost Telmisartan was more cost effective than Olmesartan. ICER was found to be 218.35.

Keywords: Olmesartan, Telmisartan, Cost Effectiveness, Hypertension.

Corresponding Author: Dr. Pankaj Kumar Singh, Tutor, Department of Pharmacology, Vardhman Institute of Medical Sciences, Pawapuri, Nalanda, Bihar.

Email: mukkukishnaut@yahoo.com

Received: March 2020

Accepted: March 2020

\section{Introduction}

Hypertension is one of the most common diseases in the world. Its origin dates back to $2600 \mathrm{BC}$ when the ancient Chinese could only suspect hypertension by the quality of one's pulse and called it hard pulse disease \& venesection $\&$ bleeding were recommended as the sole means of detecting hypertension. [1] The term "essentielle hypertonie", i.e. essential hypertension, was first quoted by the German physician Frank E in 1911 and continues to be used today. ${ }^{[2]}$ It is defined as sustained increase in blood pressure $\geq 140 / 90 \mathrm{mmHg}$, a criterion that characterizes a group of patients whose risk of hypertension related cardiovascular disease is high enough to merit medical attention. ${ }^{[3]}$ It is associated with marked morbidity, mortality \& places a high burden on health care system. The risk of both macrovascular \& microvascular complications including stroke, coronary artery disease, peripheral vascular disease, retinopathy, nephropathy \& possibly neuropathy increases with hypertension. ${ }^{[4]}$ A decrease of $2 \mathrm{mmHg}$ in BP can prevent 151,000 stroke and 153,000 coronary heart disease deaths in India. ${ }^{[5]}$ As per the
World Health Statistics 2012, of the estimated 57 million global deaths in 2008, 36 million (63\%) were due to non communicable diseases (NCDs). The largest proportion of NCD deaths is caused by cardiovascular diseases (48\%). It is seen frequently in individuals aged 40 years and also affects about half of population aged 60 years and above. ${ }^{[6]}$ In terms of attributable deaths, raised blood pressure is one of the leading behavioural and physiological risk factor to which $13 \%$ of global deaths are attributed. Nearly 1 billion adults had hypertension in $2000 \&$ this is predicted to increase to 1.56 billion by $2025 .{ }^{[7]}$ Pooled epidemiological studies show that the average prevalence of hypertension in India is $25 \%$ in urban and $10 \%$ in rural population. ${ }^{[8]}$

\section{Treatment of hypertension}

Healthy life style is mandatory. The life style modifications include weight reduction in overweight or obese patients $(\mathrm{BMI}<25 \mathrm{~kg} / \mathrm{m} 2)$, dietary salt restriction $(<6 \mathrm{~g} / \mathrm{d})$, adopting DASH (Dietary approaches to stop hypertension), eating plan which is rich in fruits, vegetables, low fat dietary products with reduced content of saturated and total fat, moderation in alcohol consumption and mental relaxation 
techniques, physical activity with brisk walk for 30 mins daily. ${ }^{[9,10]}$

Pharmacotherapeutic measures include diuretics, beta blockers, calcium channel blockers, ACE inhibitors, calcium channel blockers, angiotensin receptor antagonists include losartan, Irbesartan, Candesartan, Valsartan, Telmisartan, Olmesartan. The various drugs differ with respect to dosing, metabolism, elimination, clinical efficacy and investigational applications ARBs are well tolerated, side effects profiles are indistinguishable or even better than those of placebo. Unlike ACE inhibitors these do not induce cough. The efficacy and tolerability of ARBs, as well as other ancillary benefits, have led to their rapid uptake and widespread use. Angiotensin receptor blockers work by inhibiting the effects of a hormone called angiotensin II, which produces a number of effects in the body. All the effects of Angiotensin II are mediated by angiotensin receptors. (AT)

Olmesartan medoxomil is a non peptide angiotensin II receptor antagonist. The drug acts by selectively blocking angiotensin II type 1 receptor sites in vascular smooth muscle, thereby inhibiting the vasoconstrictor effects of angiotensin II. ${ }^{[11]}$ It is a pro-drug that is rapidly hydrolyzed into Olmesartan \& absorbed from the gastrointestinal tract into the body. The peak plasma concentration reaches in 1to $2 \mathrm{hrs}$. Oral bioavailability is not affected by food.

Telmisartan angiotensin receptor blocker (ARB) shows high affinity for the angiotensin II type 1 (AT1) receptors. In addition to blocking these receptors, it acts as a selective modulator of peroxisome proliferator-activated receptor gamma (PPAR- $\gamma$ ), a central regulator of insulin and glucose metabolism. ${ }^{[12]}$ Peak plasma levels are obtained 0.5-1 hour after oral administration and the plasma t1/2 is $~ 24$ hours. Telmisartan is cleared from the circulation mainly by biliary secretion of intact drug. The plasma clearance of Telmisartan is affected by hepatic insufficiency.

Taking into account increasing prevalence of hypertension the present study aims to compare Olmesartan \& Telmisartan, in efficacy \& cost effectiveness in patients of Stage 1 Hypertension. Treatment of hypertension is lifelong $\&$ antihypertensive drug therapy is a common target of cost cutting efforts globally.

\section{Subjects and Methods}

In this prospective open randomized parallel group comparative study 60 patients of hypertension attending the department of medicine at Vardhman Institite of Medical Sciences, Pawapuri were included. The study was approved by the institutional research committee. The study was conducted over a period of 16 weeks and consisted of 8 follow up visits. The patients were well informed about the study procedure and written informed consent was taken.

After taking a thorough history, clinical examination and biochemical investigations patients were randomly allocated to two age and sex matched groups of 30 cases each.

Group I patients were started on Olmesartan (Olmezest 20) at a dose of $20 \mathrm{mg} / \mathrm{d}$.
Group II patients were put on Telmisartan (Cresar 40) at a dose of $40 \mathrm{mg} / \mathrm{d}$.

Blood pressure was measured in supine and sitting positions at all the visits. For cost effective analysis ICER calculated i.e units of cost per benefits/effect unit. The patients fulfilling the inclusion criteria after verifying exclusion criteria were included. Inclusion and exclusion criteria were as follows:

\section{Inclusion criteria:}

1) Patients with stage I hypertension.

2) Adult male/ female aged 21 years or older and nonpregnant females not planning for conception.

3) Patient should not be on any other antihypertensive medication.

\section{Exclusion criteria:}

1) Patient with history of hypersensitivity to Olmesartan or Telmisartan.

2) Pregnant / lactating/ women planning to conceive.

3) Patient with history of refractory, secondary or malignant hypertension.

4) Patient with history of renal and hepatic disease.

5) Patient unwilling or unable to comply with the study proceedings to give informed written consent.

6) Patient with history of stroke, myocardial infarction, cerebral

7) Haemorrhage and hypertensive encephalopathy

Blood pressure, both systolic and diastolic was recorded by mercury sphygmomanometer and efficacy assessment was done by measuring blood pressure in supine and sitting positions on right arm after 10 min of rest. Blood pressure was measured at baseline and at every 2 weeks for 16 weeks. Cost- effectiveness analysis was done. The maximum retail price (MRP) of all the study drugs was noted. Mean cost of drugs for 16 weeks in both the treatment group was calculated.

The results of observations of individual patients were pooled for each group. Statistical analysis was performed using SPSS software version 20. All the analyses were performed on an intention to treat basis. For analysis of quantitative data, paired/unpaired t test was used.

\section{Results}

The [Table 1], shows mean supine systolic blood pressure in Group I and Group II at baseline, 2, 4, 6, 8, 10, 12, 14 and 16 weeks. Mean difference at baseline was $1.33 \pm 0.862$ $(\mathrm{p}=0.092)$, at 2 weeks was $2.13 \pm 0.39(\mathrm{p}=0.007) \&$ was highly significant. Mean difference at 4 weeks was $0.93 \pm 0.24 \quad(\mathrm{p}=0.064)$, at 6 weeks was $0.40 \pm 0.374$ $(\mathrm{p}=0.551)$, at 8 weeks was $0.07 \pm 0.34 \quad(\mathrm{p}=0.878)$, at 10 weeks was $0.20 \pm 0.06 \quad(\mathrm{p}=0.678)$, at 12 weeks was $0.20 \pm 0.556 \quad(\mathrm{p}=0.798)$, at 14 weeks was $1.2 \pm 0.162$ $(\mathrm{p}=0.162)$, at 16 weeks was $2.2 \pm 0.149(\mathrm{p}=0.080)$.

[Table 2] shows mean supine diastolic blood pressure in group I and group II at baseline, 2, 4, 6, 8, 10, 12, 14 and 16 
weeks. Mean Difference at baseline was $0.46 \pm 0.20$ $(\mathrm{p}=0.469)$, at 2 weeks was $3.33 \pm 0.157 \quad(\mathrm{p}=0.031)$, at 4 weeks was $1.13 \pm 0.035 \quad(\mathrm{p}=0.037)$, at 6 weeks was $1.13 \pm 0.173 \quad(\mathrm{p}=0.056)$, at 8 weeks was $1.0 \pm 0.237$ $(\mathrm{p}=0.046)$, at 10 weeks was $1.2 \pm 0.161 \quad(\mathrm{p}=0.041)$, at 12 weeks was $0.53 \pm 0.491(\mathrm{p}=0.113)$, at 14 weeks was $1.0 \pm 0.078(\mathrm{p}=0.085)$ and at 16 weeks was $1.0 \pm 0.045$ $(\mathrm{p}=0.093)$.

[Table 3] shows mean sitting systolic blood pressure in group I and group II at baseline 2, 4, 6, 8, 10, 12, 14 and 16 weeks. Mean Difference at baseline was $1.33 \pm 0.288$ $(\mathrm{p}=0.165)$, at 2 weeks was $2.26 \pm 0.272 \quad(\mathrm{p}=0.006)$, at 4 weeks was $0.93 \pm 0.216 \quad(\mathrm{p}=0.044)$, at 6 weeks was $0.40 \pm 0.236 \quad(\mathrm{p}=0.530)$, at 8 weeks was $0.20 \pm 0.192$ ( $\mathrm{p}=0.636)$, at 10 weeks was $0.20 \pm 0.116 \quad(\mathrm{p}=0.676)$, at 12 weeks was $0.06 \pm 0.025(\mathrm{p}=0.938)$, at 14 weeks was $1.26 \pm 0.448(\mathrm{p}=0.135)$ and at 16 weeks was $2.2 \pm 0.147(\mathrm{p}=$ $0.077)$.

[Table 4] shows mean sitting diastolic blood pressure in group I and group II at baseline 2, 4, 6, 8, 10, 12, 14 and 16 weeks. Mean Difference at baseline was $0.46 \pm 0.294$ $(\mathrm{p}=0.473)$, at 2 weeks was $1.26 \pm 0.293(\mathrm{p}=0.034 *)$, at 4 weeks was $1.13 \pm 0.087 \quad(\mathrm{p}=0.027 *)$, at 6 weeks was
$1.13 \pm 0.024\left(\mathrm{p}=.045^{*}\right)$, at 8 weeks was $1.13 \pm 0.092(\mathrm{p}=$ $\left.0.016^{*}\right)$, at 10 weeks was $1.2 \pm 0.185(\mathrm{p}=0.042 *)$, at 12 weeks was $0.67 \pm 0.387 \quad(\mathrm{p}=0.054 *)$, at 14 weeks was $1.07 \pm 0.119(\mathrm{p}=0.068)$ and at 16 weeks was $1.0 \pm 0.015$ ( $\mathrm{p}=0.089$ ).

[Table 5] shows MBP at baseline in Group I was 110.708 (2.87) \& 95.188 (3.07) at 16 weeks. The MBP in Group II at baseline was $111.453(2.85) \& 96.588$ (3.11) at 16 weeks. On comparing group I \& group II, the mean difference was statistically significant. $(\mathrm{p}=0.05)$

[Table 6] shows the cost effectiveness analysis of the Group I and Group II. Average cost of treatment of group I was Rs $884.80 \pm 29.49$ and group II was Rs 750.40 \pm 25.01 . Fall in MAP of group I was $15.520 \pm 0.20 \mathrm{mmHg}$ and group II was $14.865 \pm 0.26 \mathrm{~mm} \mathrm{Hg}$. Difference in cost of treatment of both the group was Rs $134.40 \pm 4.48$. Difference in the effectiveness in reduction of $\mathrm{BP}$ of both the group was0.655 \pm 0.06 .ICER was calculated by dividing the cost of treatment of both the groups to difference in effectiveness in reduction of blood pressure of both the groups. Its value comes out to be Rs 218.35 i.e In Olmesartan group to reduce the mean MBP by one $\mathrm{mm} \mathrm{Hg}$ additional cost of Rs 218.35 have to be paid by the patient.

Table 1: Comparison of SBP supine at different visits in group I and group II
\begin{tabular}{|l|l|l|l|l|}
\hline VISIT & GROUP I Mean \pm SD & GROUP II Mean \pm SD & Mean Diff \pm SD & T test (p value) \\
\hline Baseline & $147.67 \pm 3.407$ & $149.00 \pm 2.545$ & $1.33 \pm 0.862$ & 0.092 \\
\hline 2 weeks & $141.60 \pm 2.749$ & $143.73 \pm 3.139$ & $2.13 \pm 0.39$ & $0.007 * *$ \\
\hline 4 weeks & $135.87 \pm 2.029$ & $136.80 \pm 1.789$ & $0.93 \pm 0.24$ & 0.064 \\
\hline 6 weeks & $134.47 \pm 2.763$ & $134.87 \pm 2.389$ & $0.40 \pm 0.374$ & 0.551 \\
\hline 8 weeks & $131.60 \pm 1.923$ & $131.67 \pm 1.583$ & $0.07 \pm 0.34$ & 0.878 \\
\hline 10 weeks & $129.13 \pm 1.871$ & $129.33 \pm 1.844$ & $0.20 \pm 0.027$ & 0.678 \\
\hline 12 weeks & $127.73 \pm 3.050$ & $0.20 \pm 0.06$ & 0.798 \\
\hline 14 weeks & $127.93 \pm 2.993$ & $126.47 \pm 3.549$ & $1.20 \pm 0.556$ & 0.162 \\
\hline 16 weeks & $125.27 \pm 2.993$ & $127.00 \pm 4.864$ & $2.20 \pm 0.149$ & 0.080 \\
\hline
\end{tabular}

Table 2: Comparison of DBP supine at different visits in group I and group II
\begin{tabular}{|l|l|l|l|l|}
\hline VISIT & GROUP I Mean \pm SD & GROUP II Mean \pm SD & Mean Diff \pm SD & T test (p value) \\
\hline Baseline & $92.07 \pm 2.545$ & $92.53 \pm 2.345$ & $0.46 \pm 0.20$ & 0.469 \\
\hline 2 weeks & $86.60 \pm 2.415$ & $89.93 \pm 2.258$ & $3.33 \pm 0.157$ & $0.031^{*}$ \\
\hline 4 weeks & $85.20 \pm 2.074$ & $86.33 \pm 2.039$ & $1.13 \pm 0.035$ & $0.037^{*}$ \\
\hline 6 weeks & $83.00 \pm 2.334$ & $84.13 \pm 2.161$ & $1.13 \pm 0.173$ & $0.056^{*}$ \\
\hline 8 weeks & $81.73 \pm 2.016$ & $82.20 \pm 1.779$ & $1.00 \pm 0.237$ & $0.046^{*}$ \\
\hline 10 weeks & $81.00 \pm 2.149$ & $1.20 \pm 0.161$ & $0.041^{*}$ \\
\hline 12 weeks & $80.60 \pm 1.499$ & $81.13 \pm 1.008$ & $0.53 \pm 0.491$ & 0.113 \\
\hline 14 weeks & $80.60 \pm 2.175$ & $81.60 \pm 2.253$ & $1.00 \pm 0.078$ & 0.085 \\
\hline 16 weeks & $80.33 \pm 2.294$ & $81.33 \pm 2.249$ & $1.00 \pm 0.045$ & 0.093 \\
\hline
\end{tabular}

\begin{tabular}{|c|c|c|c|c|}
\hline VISIT & GROUP I Mean \pm SD & GROUP II Mean \pm SD & Mean Diff \pm SD & T test (p value) \\
\hline Baseline & $147.87 \pm 3.521$ & $149.20 \pm 3.809$ & $1.33 \pm 0.288$ & 0.165 \\
\hline 2 weeks & $141.67 \pm 2.675$ & $143.93 \pm 2.947$ & $2.26 \pm 0.272$ & $0.006 * *$ \\
\hline 4 weeks & $136.07 \pm 1.856$ & $137.00 \pm 1.640$ & $0.93 \pm 0.216$ & $0.044 *$ \\
\hline 6 weeks & $134.53 \pm 2.569$ & $134.93 \pm 2.333$ & $0.40 \pm 0.236$ & 0.530 \\
\hline 8 weeks & $131.73 \pm 1.721$ & $131.93 \pm 1.529$ & $0.20 \pm 0.192$ & 0.636 \\
\hline 10 weeks & $129.20 \pm 1.789$ & $129.40 \pm 1.905$ & $0.20 \pm 0.116$ & 0.676 \\
\hline 12 weeks & $127.93 \pm 2.993$ & $127.87 \pm 2.968$ & $0.06 \pm 0.025$ & 0.938 \\
\hline 14 weeks & $125.27 \pm 2.993$ & $126.53 \pm 3.441$ & $1.26 \pm 0.448$ & 0.135 \\
\hline 16 weeks & $124.87 \pm 4.659$ & $127.07 \pm 4.806$ & $2.20 \pm 0.147$ & 0.077 \\
\hline
\end{tabular}

*significant $(\mathrm{p}<0.05) * *$ highly significant $(\mathrm{p}<0.01) * * *$ very highly significant $(\mathrm{p}<0.001)$ 
Table 4: Comparison of DBP sitting at different visits in group I and group II

\begin{tabular}{|l|l|l|l|l|}
\hline VISIT & GROUP I Mean \pm SD & GROUP II Mean \pm SD & Mean Diff \pm SD & T test (p value) \\
\hline Baseline & $92.27 \pm 2.612$ & $92.73 \pm 2.318$ & $0.46 \pm 0.294$ & 0.473 \\
\hline 2 weeks & $88.87 \pm 2.389$ & $90.13 \pm 2.096$ & $1.26 \pm 0.293$ & $0.034^{* *}$ \\
\hline 4 weeks & $85.40 \pm 1.976$ & $86.53 \pm 1.889$ & $1.13 \pm 0.087$ & $0.027^{*}$ \\
\hline 6 weeks & $83.07 \pm 2.148$ & $84.20 \pm 2.124$ & $1.13 \pm 0.024$ & $0.045^{*}$ \\
\hline 8 weeks & $81.87 \pm 1.814$ & $83.00 \pm 1.722$ & $1.13 \pm 0.092$ & $0.016^{*}$ \\
\hline 10 weeks & $81.07 \pm 2.148$ & $82.27 \pm 2.333$ & $1.20 \pm 0.185$ & $0.042^{*}$ \\
\hline 12 weeks & $80.60 \pm 1.499$ & $81.27 \pm 1.112$ & $0.67 \pm 0.387$ & $0.054^{*}$ \\
\hline 14 weeks & $80.60 \pm 2.175$ & $81.67 \pm 2.294$ & $1.07 \pm 0.119$ & 0.068 \\
\hline 16 weeks & $80.40 \pm 2.253$ & $81.40 \pm 2.238$ & $1.00 \pm 0.015$ & 0.089 \\
\hline
\end{tabular}

Table 5: Comparison of mean blood pressure in group I and group II
\begin{tabular}{|l|l|l|l|l|}
\hline MBP \pm SD & MBP \pm SD & Mean Difference \pm SD & t-test P value \\
\cline { 1 - 2 } & $110.708 \pm 2.87$ & $95.188 \pm 3.07$ & $15.520 \pm 0.20$ & 0.05 \\
\hline GROUP II & $111.453 \pm 2.85$ & $96.588 \pm 3.11$ & $14.865 \pm 0.26$ & \\
\end{tabular}

Table 6: Cost effectiveness analysis.

\begin{tabular}{|l|l|l|l|l|l|}
\hline Parameters & GROUP I & GROUP II & Difference in cost C1-C2 & Difference in effectiveness E1-E2 & ICER \\
\hline Cost (Rs) & 884.80 & 750.40 & $134.40 \pm 4.48$ & 0.655 & \pm 0.06 \\
& \pm 29.49 & \pm 25.01 & & & \\
Fall in mean & 15.520 & 14.865 & & & \\
MBP (mmHg) & \pm 0.20 & \pm 0.26 & & & \\
\hline
\end{tabular}

\section{Discussion}

Hypertension is a major contributor to cardiovascular disease and a leading cause of stroke, myocardial infarction, heart failure and kidney disease. Although benefits of blood pressure reduction have been well documented, the majority of patients remain undertreated and poorly controlled. Since hypertension is a chronic condition it is mandatory to ensure proper patient compliance to antihypertensive therapy. Medication costs, side effects of the drugs, poor quality of life are some of the main factors contributing to poor patient compliance.

\section{Efficacy}

Systolic Blood Pressure In Supine Position: In the present study, systolic blood pressure in supine position fell from mean of 147.67 (3.407) at baseline to $124.80(4.715) \mathrm{mm} \mathrm{Hg}$ after 16 weeks of treatment in group I. There was lowering of BP on every visit \& at 16 weeks there was a mean difference of $22.87 \mathrm{~mm} \mathrm{Hg}$ from baseline \& this lowering was significant at 2 weeks [Table 1]. In group II supine systolic blood pressure fell on each visit from mean 149(3.991) at baseline to 127(4.864) $\mathrm{mm} \mathrm{Hg}$ after 16 weeks of treatment. At 16 weeks there was a mean difference of 22 $\mathrm{mm} \mathrm{Hg}$ from baseline.

\section{Diastolic Blood Pressure In Supine Position:}

In the present study, diastolic blood pressure in supine position fell from mean $92.07(2.545)$ at baseline to 80.33(2.294) $\mathrm{mm} \mathrm{Hg}$ after 16 weeks of treatment in group I There was lowering of BP on every visit and was significant at 2,4,6,8 \& 10 weeks. [Table 2] In group II supine diastolic blood pressure fell on each visit from mean of baseline $92.53(2.345)$ to $81.33(2.249) \mathrm{mm} \mathrm{Hg}$ after 16 weeks of treatment. At 16 weeks there was mean difference of $11.20 \mathrm{~mm} \mathrm{Hg}$ from baseline.

Systolic Blood Pressure In Sitting Position:

In the present study, systolic blood pressure in sitting position fell from mean $147.87(3.521)$ at baseline to 124.87(4.659) $\mathrm{mm} \mathrm{Hg}$ after 16 weeks of treatment in group I. There was lowering of BP on every visit which was significant at 2, 4 weeks. [Table 3] At 16 weeks there was mean difference of $23 \mathrm{~mm} \mathrm{Hg}$ from baseline. In group II sitting systolic blood pressure fell on each visit from mean 149.20 (3.809) at baseline to 127.07 (4.806) $\mathrm{mm} \mathrm{Hg}$ after 16 weeks of treatment. At 16 weeks there was mean difference of $22.13 \mathrm{~mm} \mathrm{Hg}$ from baseline.

\section{Diastolic Blood Pressure InSitting Position:}

In the present study, diastolic blood pressure in sitting position fell from mean of $92.27(2.612)$ at baseline to $80.40(2.253) \mathrm{mm} \mathrm{Hg}$ after 16 weeks of treatment in group I. There was lowering of BP at every visit \& was significant at $2,4,6,8, \& 10$ weeks [Table 4]. At 16 weeks there was mean difference of $11.87 \mathrm{~mm} \mathrm{Hg}$ from baseline. In group II sitting diastolic blood pressure fell on every visit from mean 92.73(2.318) at baseline to $81.40(2.238) \mathrm{mmHg}$ after 16 weeks of treatment. At 16 weeks there was mean difference of $11.33 \mathrm{~mm} \mathrm{Hg}$ from baseline.

\section{Mean blood Pressure:}

In group I mean MBP at baseline was 110.708 (2.87) \& at 16 weeks was 95.188 (3.07). In group II mean MBP at baseline was 111.453 (2.85) \& at 16 weeks was 96.588 (3.11). Mean difference in group was 15.520 in group I \& 14.865 in group II. However on comparing the two groups the difference was found to be statistically significant $(\mathrm{p}=0.05)$. There was more lowering of blood pressure in group I (olmesartan group)

Cost effectiveness 
The daily cost with Olmesartan (Olmezest 20) was Rs 7.9 \& Rs 884.8 for 16 weeks and Telmisartan (Cresar 40) daily cost was Rs 6.7 \& Rs 750.4 for 16 weeks. For Yearly treatment Olmesartan cost Rs 2812.4 \& Telmisartan costs Rs 2385.2.The cost effectiveness analysis of the Group I and Group II was done. Average cost of treatment of group I was Rs $884.80 \pm 29.49$ and group II was Rs $750.40 \pm$ 25.01. Fall in MAP of group I was $15.520 \pm 0.20 \mathrm{mmHg}$ and group II was $14.865 \pm 0.26 \mathrm{~mm}$ Hg. ICER was calculated comes out to be Rs 218.35 i.e In Olmesartan group to reduce the mean MBP by one $\mathrm{mm} \mathrm{Hg}$ additional cost of Rs 218.35 have to be paid by the patient. Brunner, ${ }^{[13]}$ in 2004 conducted a study, patients were randomized to Olmesartan $(2.5-80 \mathrm{mg})$ or placebo once daily. It was found that Olmesartan produced a dose dependent decrease in diastolic \& systolic blood pressures as compared to placebo which is consistent with our study. Nakayama et al, ${ }^{[14]}$ in 2007 conducted a study to compare the effects of Olmesartan and Telmisartan on blood pressure, \& concluded that Olmesartan lowered mean systolic and diastolic blood pressure more significantly than did Telmisartan which is also consistent with our study. In Jadhav et al, ${ }^{[15]}$ study Patients were randomized to either olmesartan or telmisartan monotherapy, Olmesartan showed a Significant lowering of average $24 \mathrm{hrs} \mathrm{SBP}$ as compared to telmisartan which is also consistent with our study Sasaki et al, ${ }^{[16]}$ evaluated the effects of telmisartan and olmesartan \&concluded that telmisartan is more beneficial than olmesartan in reducing blood pressure in the early morning in patients with hypertension which is not consistent with our study. Arao et $\mathrm{al}^{[17]}$ conducted a crossover study in hypertensive patients with type 2 diabetes, \& concluded that there is no significant difference in blood pressure reduction rate between Olmesartan \& Telmisartan treatment groups. This is also not consistent with our study.

\section{Cost Effectiveness}

Difference in cost of treatment of both the groups was Rs134.40 \pm 4.48 . Difference in the effectiveness in reduction of BP of both the group was $0.655 \pm 0.06$. ICER value comes out to be Rs 218.35.Telmisartan was found to be cost effective. There was no study published that compares cost effectiveness of Olmesartan \& Telmisartan. But Borsema et al, ${ }^{[18]}$ conducted a study to evaluate cost effectiveness, showed that treatment with olmesartan versus losartan, valsartan, and irbesartan resulted in a significantly larger decrease in BP (11.5 vs 8.2, 7.9and $9.9 \mathrm{mmHg}$ [p < $0.05]$, respectively) and consequently more complications averted. Cost effectiveness for olmesartan, losartan, valsartan, and irbesartan was estimated at euro 39100, euro 77100, euro70700, and euro 50,900 per cardiovascular complication averted, respectively. The incremental cost effectiveness analysis indicated the most favorable costeffectivenes outcome for olmesartan, with lower costs and less cardiovascular complications for olmesartan compared with the other three ARBs.

Both Olmesartan and Telmisartan effectively lowered systolic and diastolic blood pressure in supine and sitting positions, Olmesartan lowers Blood pressure more than Telmisartan. Taking into account cost Telmisartan is more cost effective. The limitation of our study was that sample size is less \& can be increased to increase reliability and blinding can be done.

\section{Conclusion}

Both Olmesartan and Telmisartan belong to the same antihypertensive drug class, effectively reduce systolic and diastolic blood pressure at various visits. Taking into account Total cost Telmisartan was more cost effective than Olmesartan. ICER was found to be 218.35.

\section{References}

1. Basile JN, Ventura H. A historical look at hypertension: celebrating 100 years with the Southern Medical Association. South Med J 2006;99(12):1412-3.

2. Esunge PM. From blood pressure to hypertension: the history of research. Journal of the Royal Society of Medicine 199;84(10):621.

3. Michel T, Hoffman B. Treatment of Myocardial Ischemia and Hypertension. In: Brunton LL, Chabner BA, Knollmann BC editors. Goodman \& Gilman's The Pharmacological Basis of Therapeutics. 12th ed. New York: McGraw Hills; 2011.p. 766.

4. Venkateswaramurthy M, Dileep M, Perumal P. Management of Hypertension in patients with Diabetes. Asian J Pharm Clin Res 2011;4 Suppl(2):40-41.

5. Gupta R. Trends in Hypertension. J Hum Hypertension 2004;8(2):738.

6. Kearney PM, Whelton M, Reynolds K, Muntner P, Whelton PK, He J. Global burden of hypertension: Analysis of worldwide data. Lancet 2005;365:217-23.

7. Pradeepa R, Mohan V. Hypertension \& pre-hypertension in developing countries. Indian J Med Res 2008;128:688-690.8

8. Rodrigo M, Premranjan P, Richard W. Diabetes and Hypertension. Natural Clinical Practice 2007;3(10).

9. McGhan Williams F. Introduction to Pharmacoeconomics. In: Arnold Renee JG, editors. Pharmacoeconomics from theory to practice. 10th ed. USA: Boca Raton CRC Press; 2010. p.4.

10. Chobanian AV, Bakris GL, Black HR, Cushman C, Green Lee A, Izzo JL et al. The Seventh Report of the Joint National Committee on Prevention, Detection, Evaluation and Treatment of High Blood Pressure: The JNC 7 Report. JAMA 2003;289(19):560-72.

11. Norwood D, Evans B III, Smith B, Honeywell M. Olmesartan Medoximil for Hypertension: A Clinical Review. Drug Forecast 2002;27:611-18.

12. Yamagishi S, Takeuchi M. Telmisartan is a promising cardiometabolic sartan due to its unique PPAR-gamma inducing activity. Med hypotheses 2005;64.

13. Brunner HR. Clinical efficacy and Tolerability of Olmesartan. Clin Ther 2004;26:28-32.

14. Nakayama S, Watada H, Mita T, Ikeda F, Shimizu T, Uchino H, et al. Comparison of effects of olmesartan and telmisartan on blood pressure and metabolic parameters in Japanese early stage type 2 diabetes with hypertension. Fundam Clin Pharmacol 2007;21(2):181-90.

15. Jadhav UM, Anala K, Soniya P. Comparative efficacy of telmisartan $40 \mathrm{mg}$ and olmesartan $20 \mathrm{mg}$ on 24 hours ambulatory blood pressure monitoring in hypertension. The Journal of Clinical Hypertension 2012; 14Suppl (1):20.

16. Sasaki T, Noda $Y$, Yasuoka $Y$, Irino $H$, Abe $H$, Adachi $H$ et al. Comparison of the Effects of telmisartan \& olmesartan on home blood pressure, Glucose \& lipid profiles in Patients with Hypertension chronic heart failure \& metabolic syndrome. Hypertension Research 2008;31:921-29.

17. Arao T, Okada Y, Mori Y, Nishida K, Tanaka Y. Antihypertensive \& metabolic effects of high dose Olmesartan \& Telmisartan in type 2 diabetes patients with hypertension. Endocrine journal 2013; 


$$
\text { 60(5):563-570. }
$$

18. Boersma C, Voors AA, Visser ST,De Jong VBLT, Postma MJ. Cost effectiveness of angiotensin receptor blocker monotherapy in
Patients with hypertension in the Netherlands: a comparative analysis using clinical trial and drug utilization data. Am J Cardiovasc Drugs 2010;10(1):49-54.

Copyright: (C) the author(s), 2020. It is an open-access article distributed under the terms of the Creative Commons Attribution License (CC BY 4.0), which permits authors to retain ownership of the copyright for their content, and allow anyone to download, reuse, reprint, modify, distribute and/or copy the content as long as the original authors and source are cited.

How to cite this article: Singh PK, Kumar S. Comparative Study to Evaluate Efficacy \& Cost Effectiveness of Olmesartan versus Telmisartan, In Patients of Stage I Hypertension. Asian J. Med. Res. 2020;9(1):PC01-PC06.

DOI: dx.doi.org/10.47009/ajmr.2020.9.1.PC1

Source of Support: Nil, Conflict of Interest: None declared. 